\title{
Biochemical Response Comparisons of a Competitive Microcycle Vs. Congested Fixture Periods in Elite Level European Champions League Soccer Players
}

\author{
Adam L Owen ${ }^{1 *}$, Leo Djaoui ${ }^{1}$, Alexandre Dellal ${ }^{1,2}$, Osman Ates $^{3,4}$ and Bruno Mendes \\ ${ }^{1}$ Univ Lyon, University Claude Bernard Lyon, France \\ ${ }^{2}$ FIFA Medical Centre of Excellence, Sport Science and Research Department, France \\ ${ }^{3}$ Sport Science Faculty, University of Istanbul Cerrahpasa, Turkey \\ ${ }^{4}$ Medipol Basaksehir FC, Turkey \\ ${ }^{5}$ Sport Science Department Everton Football Club, England
}

Submission: July 11, 2019; Published: August 05, 2019

*Corresponding author: Adam L Owen, University Claude Bernard Lyon, LIBM EA7424, Villeurbanne, France

\begin{abstract}
The aim of this investigation was to analyses differences between post-game biochemical responses in congested (CP, when two consecutive games were played within 4 days or less) vs. non-congested (NCP, when two consecutive games were played within 5 days or more) periods. Assessment of creatine kinase (CK) and salivary cortisol (sCort) and immunoglobulin-A (sIgA) were performed across 12 separate training macrocycles of 14 competitive professional matches. The NCP analysis revealed significantly higher CK values from one day after match day $(\mathrm{MD}+1)$ than values found in $\mathrm{MD}$ and $\mathrm{MD}+2$ (Effect size (ES): 0.82-1.13, $\mathrm{p}<0.0033)$. The $\mathrm{CP}$ analysis revealed no significant changes in $\mathrm{CK}$ values between MD, MD+1 and MD+2. Higher values on MD+2 in CP vs. NCP were also revealed (ES:0.27, p<0.05). No significant changes in sCort and sIgA were observed. Congested competitive periods induce significant biochemical changes revealed amongst elite soccer players that should influence their preparation and management.
\end{abstract}

Keywords: Cortisol; Creatine kinase; Immune function; Football; Fixture congestion

\section{Introduction}

Across the course of an elite soccer season, the continual training, playing demands and additional stressors imposed upon players can lead to significant changes in haematological profiles [1]. Soccer is characterized by high intensity intermittent activity patterns. Players perform numerous intensive accelerations and decelerations in conjunction with high-intensity activities including sprinting, jumping, kicking and changing direction $[2,3]$. Such activity can cause muscle fiber damage. In the literature, CK is commonly used to examine exercise severity and exercise-induced muscle damage [4-6]. A soccer-game impose on players to repeat high numbers of very intensive accelerations and decelerations [7] that involve both concentric and eccentric contractions of the lower limb muscles, which may induce micro damages and structure changes to the muscles [8,9]. CK values have been shown to increase between $24-48 \mathrm{~h}$ post-competitive soccer play, and to return to baseline approximately $72 \mathrm{~h}$ or more
[10-13], however, interestingly the variation across a typical competitive week of $\mathrm{CK}$ values linked to training load (TL) distribution have to date not been investigated. The presence of muscle damage after a soccer match could potentially impair subsequent training and competition performances, however further research is needed.

In addition, with CK analysis, and according to previous literature in this area, salivary cortisol (sCort) is another biochemical marker that is highly responsive to exercise and is directly related to the catabolic activity [14]. Cortisol has recently been suggested as a relevant indicator to monitor recovery in soccer, in response to the induced stress [15]. Induced stress by exercise is associated with the stimulation of the hypothalamic corticotropin-releasing hormone, pituitary adrenocorticotropic hormone release and the subsequent production of sCort $[16,17]$. Increased levels of sCort as a result of accumulated 
stress-inducement, can negatively impact mucosal immunity, subsequently increasing the risk of illness [18]. Based on the fact elite soccer players are faced with increased congested fixture schedules at domestic, European and International levels, increasing the knowledge of biochemical fatigue and recovery kinetics may assist in the TL management during congested periods (CP) in order to avoid injury and optimizing physical recovery and/or performance. Recent findings have suggested that congested fixture periods are associated with perturbations in mucosal immunity [19] and an elevation of injury incidence $[18,20,21]$ observed a greater reduction in mean relative salivary SIgA concentration following an intensive competition period (nine games in eight weeks) compared with a less competitive period in rugby union (two games in four weeks) (29\% vs $9 \%$ decrease in salivary SIgA). Moreover, the decrease in absolute SIgA concentrations were associated with a corresponding increase in sCort [18]. Furthermore, Mohr et al. [22] observed how playing three matches per week increased muscle damage, inflammatory and oxidative stress responses. Moreover, it was observed that the second match played after three days of recovery induced higher muscle damage and inflammation vs. the third game played after four days of recovery [22]. This maybe as a result to lingering muscle damage from first game causing added CK release as in poor muscular recovery. It might therefore be suggested that differences exist between periods of matches with three days in between, (e.g. CP) [23] and periods of matches with four days and more in between (non-congested period, NCP). Changes in these parameters have been previously associated to fatigue related to match play $[12,15]$. However, to our knowledge, no previous investigation has analysed the differences between CP vs. NCP regarding the physical and biochemical incidences of match play at any level, especially in elite level soccer players. Therefore, the novel and unique aim of the current investigation was to explore the evolution of CK and sCort during the in-season competitive phase, and analyses differences between congested vs. non-congested competitive phases in relation to player's post-match fatigue kinetics.

\section{Methods}

\section{Experimental approach to the problem}

To explore the evolution of CK and sCort during the in-season competitive phase, and analyse differences between CP vs. NCP in relation to player's post-match fatigue kinetics, all testing procedures were performed across the first phase of the 20162017 season as to ensure no significant changes in physical status or fatigue was apparent and to maintain consistency of testing and sample collection [24]. The data set obtained, included 12 separate training macrocycles, inclusive of 14 competitive matches between August and October. The CP ( $\mathrm{n}=5$ macrocycles) was determined as a macrocycle including 2 competitive matches within 4 days or less. During this period samples were collected on match day (MD), $24 \mathrm{~h}(\mathrm{MD}+1)$ and $48 \mathrm{~h}$ post-match $(\mathrm{MD}+2)$. The NCP ( $n=7$ macrocycles) was determined as a microcycle including 2 competitive matches within 5 days or more. During
NCP, samples were collected four, three and two days before the match (MD-4, MD-3 and MD-2, respectively), and on MD, MD+1 and $M D+2$. Although a total number of 59 training sessions were during the protocol period, only 28 training sessions were included in the procedure analysis, with a total number of 535 observations, to ensure a design internal validity and avoid sample-collecting bias.

\section{Subjects}

Twenty-three $(n=23)$ elite male professional soccer players participated in this investigation. Players participating within this study were at the time competing at the elite level of European soccer within the UEFA Champions League and were recognized as the most successful domestic team in their national league. At the initiation of the study, players involved had a mean \pm SD age of $24.4 \pm 4.1$ (range: 18 to 34 ) years, stature of $182.5 \pm 2.9$ (168 to 195 ) $\mathrm{cm}$, and body mass of $77.8 \pm 5.4 \mathrm{~kg}$ (61.2 to 93.5 ) $\mathrm{kg}$. All participants had been playing soccer for 8 years or more and all but four of them were competing for their respective international team. Participants were informed that they were free to withdraw their individual data from the study at any time. Informed consent was obtained from all individual participants included in the study. The procedure performed in the present study was in accordance with the ethical standards of the institutional committee and with the 1964 Helsinki declaration and its later amendments or comparable ethical standards.

\section{Procedure}

Throughout the investigation, players were allowed to consume commercially available isotonic sports drinks ad libitum during the training sessions and were also instructed to maintain normal daily food and water intake and CHO sport drinks during training when required. No additional dietary interventions were undertaken. Only data from players who met the following inclusion criteria similar to Coelho et al. [24] was assessed and included within the study $(n=23)$. The established inclusion criteria required players had to have a minimum participation of $75 \mathrm{~min}$ per game, not injured or ill on the collecting day or during the match and participated to the collective training sessions throughout the course of the macrocycle. If a player was injured, at any point through the macrocycle, their data for that period was excluded from the assessment until they returned to normal collective training with the rest of the group to play the official matches. The mean number of games played per player was 5.56 (range [1-11]). All blood sample collection was performed within the lab facilities of the club pre-training session. Trewin et al. [25] recently reviewed the influence of situational and environmental factors on physical outputs in soccer match-play. It was concluded from the findings that environmental factors influence the variability in match-running performance from match-to-match. As a result, taking the present design into account, many confounding variables may affect the data. Within this study all training and competitive match play was performed on natural turf pitches; the playing system adopted by the team 
remained in a 4-2-3-1 formation between the congested vs the non-congested fixtures.

\section{Training Load Assessment}

Across the training sessions for the investigation, each individual player's motion pathways were tracked using a 10 Hertz GPS device (Viper, Statsport, Ireland). Research has shown this system to be a valid and reliable marker of assessment for monitoring team player's movement demands [26]. For the purpose of this study, absolute (in meters) and relative (in meters per minute) total distance covered (TDC), high-speed running (HSR: $>19.8 \mathrm{~km} . \mathrm{h}-1$ ) and absolute (in number) and relative (in number per minute) Accel $(>1 \mathrm{~ms}-2)$, Decel $(<-1$ ms-2)and sprints ( $>24.4 \mathrm{kmh}-1$ ). The total values taken from the complete training sessions were used for analysis. The players wore the same GPS unit for each training session in order to keep the validity of the data.

\section{Creatine Kinase Assessment}

For the enzymatic measurement of plasma CK concentration, $32 \mu \mathrm{L}$ capillary blood samples were obtained from the fingertip of the index finger of the selected players pre-training and recovery days throughout the course of the investigation. The fingertip was cleaned with 95\% ethanol and dried with cotton wool to remove excess liquid; an automatic lancet device was used to draw blood before a heparinized capillary tube (Reflotron ${ }^{\circledR}$, catalog No. 955053202) was used to collect the sample. The capillary blood sample was then immediately placed onto a CK test strip (Reflotron $囚$, catalog No. 1126695) through the use of a pipette and analyzed via the Boehringer Mannheim Reflotron Analyzer®.

\section{Saliva Sampling}

Resting saliva samples were obtained pre-breakfast throughout the study period on each training and recovery day.
Free days away from the training facility were not measured due to logistics. All participants rinsed their mouth with water 10 min prior to saliva collection. Unstimulated, whole saliva was collected using an IPRO oral fluid collector (OFC, IPRO Interactive, Wallingford, UK). Participants rested one OFC swab on top of their tongue and closed their mouth to stimulate the saliva release. Upon $0.5 \mathrm{~mL}$ level of saliva being absorbed by the OFC, an indicator line of the swab stem turned bright blue at which point the OFC was removed from the participant's mouth and placed into a $3 \mathrm{~mL}$ buffer solution for analysis. Upon required saliva being taken, samples were then passed immediately to a test administrator and analysed in order to determine the sCort and the sIgA concentration using an IPRO Reader (Ipro Interactive, Wallingford, UK). This method has previously been validated for the determination of these two hormones in the sporting environment [27-28].

\section{Statistical analysis}

Variables distribution was first tested with the ShapiroWilk normality test. When significant, a one-way analyse of variance (ANOVA) with repeated measure was used to examine the differences in the biochemical markers between days. Then t-test paired comparisons were used to point the differences. When non-significant, a non-parametric Friedman test was used, and then non-parametric paired Wilcoxon tests were assessed to point the differences. T-test paired comparisons and non-parametric Wilcoxon tests were also used to determine the differences between congested and non-congested weeks. Bonferroni's correction was applied. The level of significance was set at $\mathrm{p}<0.05$ for congested vs. non-congested comparisons and at $\mathrm{p}<0.0033$ for days-to-days comparisons. For all analysis, the effect size (ES) was calculated and evaluated as small: $<0.50$, moderate: $0.50-0.80$, or large: $>0.80$, as described by Cohen [29]. Coefficient of variation (CV) was also calculated from the ratio standard deviation (sd)/mean.

\section{Results}

Table 1: Plasma creatine kinase, salivary Iga and salivary cortisol during congested and non-congested weeks in elite soccer players.

\begin{tabular}{|c|c|c|c|c|c|c|c|c|c|}
\hline & Markers & MD-4 & MD-3 & MD-2 & MD-1 & MD & MD+1 & $\mathrm{MD}+2$ & $\begin{array}{l}\text { Differences } \\
(p<0.0033)\end{array}$ \\
\hline \multirow{5}{*}{ Non-congested week } & $\mathrm{TDC}\left(\mathrm{m} \cdot \mathrm{min}^{-1}\right)$ & $79.5 \pm 16.4$ & $89 \pm 10.3$ & $68.2 \pm 11.1$ & $41 \pm 9.45$ & NA & Rest & $79 \pm 8.46$ & $\begin{array}{c}\text { MD-3>(MD- } \\
4=\mathrm{MD}+2)>\text { MD- } \\
2>\text { MD- }\end{array}$ \\
\hline & $\operatorname{HSR}\left(\mathrm{m} \cdot \mathrm{min}^{-1}\right)$ & $0.84 \pm 0.80$ & $\begin{array}{c}0.67 \pm \\
0.57\end{array}$ & $0.59 \pm 0.65$ & $0.15 \pm 0.26$ & NA & Rest & $0.1 \pm 0.26$ & $\begin{array}{c}(\mathrm{MD}-4=\mathrm{MD}- \\
3=\mathrm{MD}-2)>(\mathrm{MD}- \\
1=\mathrm{MD}+2)\end{array}$ \\
\hline & Accelerations(n) & $46.3 \pm 15.4$ & $\begin{array}{c}38.8 \pm \\
15.9 \\
\end{array}$ & $27 \pm 13.2$ & $37.7 \pm 11.2$ & NA & Rest & $25.3 \pm 10.1$ & $\begin{array}{l}\text { MD- } 4>M D+2>(M- \\
\text { D3=MD-2=MD-1) }\end{array}$ \\
\hline & CK $\left(U . L^{-1}\right)$ & $145 \pm 54.3$ & $283 \pm 185$ & $174 \pm 118$ & NA & $183 \pm 118$ & $295 \pm 133$ & $176 \pm 111$ & $\begin{array}{c}\mathrm{MD}+1>(\mathrm{MD}-4= \\
\mathrm{MD}-2=\mathrm{M}- \\
\mathrm{D}=\mathrm{MD}+2)\end{array}$ \\
\hline & sCort $\left(\right.$ nmol. $\left.\mathrm{L}^{-1}\right)$ & $86.9 \pm 123$ & $134 \pm 104$ & $95.7 \pm 75.7$ & NA & NA & $86 \pm 61.7$ & $98.5 \pm 73.2$ & - \\
\hline
\end{tabular}


Journal of Complementary Medicine \& Alternative Healthcare

\begin{tabular}{|c|c|c|c|c|c|c|c|c|c|}
\hline \multirow{6}{*}{ Congested week } & TDC $\left(\mathrm{m} \cdot \mathrm{min}^{-1}\right)$ & - & - & NA & $\begin{array}{c}52.6^{*} \pm \\
8.45\end{array}$ & NA & Rest & $82.4 \pm 11.6$ & $\begin{array}{c}\mathrm{MD}+2>\mathrm{MD}-1 \\
(\mathrm{p}=0.01)\end{array}$ \\
\hline & $\operatorname{HSR}\left(\mathrm{m} \cdot \mathrm{min}^{-1}\right)$ & - & - & NA & $\begin{array}{c}0.24{ }^{*} \pm \\
0.24\end{array}$ & NA & Rest & $0.17 \pm 0.32$ & - \\
\hline & Accelerations (n) & - & - & NA & $\begin{array}{c}42.0 * \pm \\
12.7\end{array}$ & NA & Rest & $\begin{array}{c}17.8 * \pm \\
12.24\end{array}$ & $\mathrm{MD}-1>\mathrm{MD}+2$ \\
\hline & CK $\left(U . L^{-1}\right)$ & - & - & NA & NA & $221 \pm 155$ & $301 \pm 160$ & $206 * \pm 116$ & - \\
\hline & sCort(nmol. $\left.\mathrm{L}^{-1}\right)$ & - & - & NA & NA & $56.7 \pm 40.7$ & $93.7 \pm 82.4$ & $88 \pm 53.1$ & - \\
\hline & $\operatorname{sIg} \mathrm{A}\left(\mu \mathrm{g} \cdot \mathrm{mL}^{1}\right)$ & - & - & NA & NA & NA & $304 \pm 193$ & $266 \pm 163$ & - \\
\hline
\end{tabular}

MD-4, MD-3, MD-2 and MD-1 = four, three, two and one days before the match, respectively

$\mathrm{MD}=$ match day; $\mathrm{MD}+1, \mathrm{MD}+2$ = one and two days after the match, respectively.

$\mathrm{CK}=$ creatine kinase

sCort = salivary cortisol

TDC $=$ total distance covered

HSR $=$ High-speed running $\left(>\mathrm{km} \cdot \mathrm{h}^{-1}\right)$

$\mathrm{NA}=$ non-assessed

* Higher than the same measure during non-congested week $(p<0.05)$

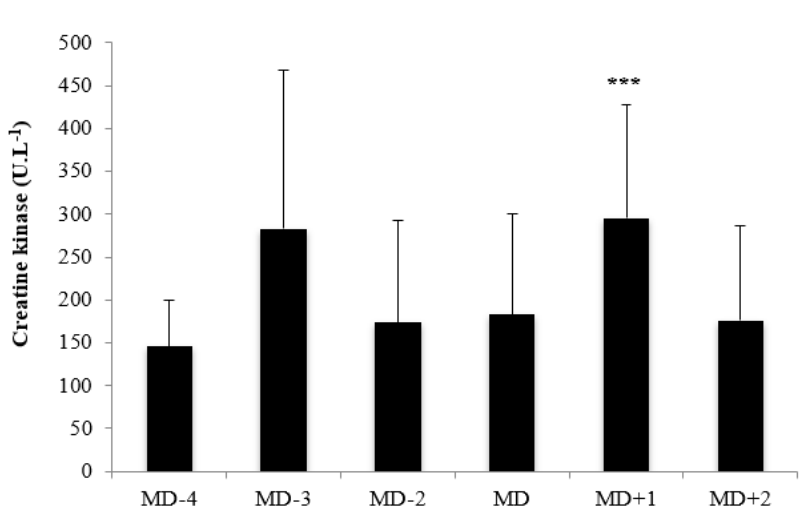

Figure 1: Creatine kinase evolutions across a typical competitive week in elite soccer players.

MD-4, MD-3, MD-2 = four, three and two days before the match, respectively

$\mathrm{MD}=$ match day; $\mathrm{MD}+1, \mathrm{MD}+2=$ one and two days after the match, respectively.

*** MD+1 > MD-2 and MD+2 ( $<<0.001)$

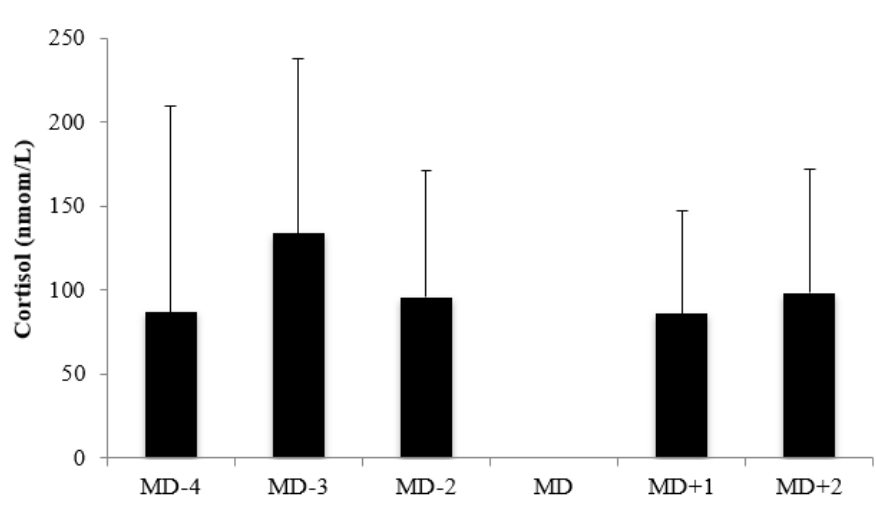

Figure 2: Cortisol evolutions across a typical competitive week in elite soccer players.

MD-4, MD-3, MD-2 = four, three and two days before the match, respectively

$M D=$ match day; $M D+1, M D+2=$ one and two days after the match, respectively.

Data were presented as mean \pm sd throughout. Biochemical marker and training load changes across the weeks are presented in Table 1. During the typical NCP, CK values in MD+1 (CV: 45\%) were significantly higher than values in MD-4 (ES: 
1.11, CV: 37\%), MD-2 (ES: 0.89, CV: 68\%), MD (ES: 0.82, CV: $64 \%)$ and $\mathrm{MD}+2$ (ES: $0.93, \mathrm{CV}: 63 \%)(\mathrm{p}<0.01)$ while $\mathrm{CK}$ values reported in MD-3 (CV: 65\%) were higher than those reported in $\mathrm{MD}+2$ (ES: 0.82, $\mathrm{p}<0.01$ ) and $\mathrm{MD}-4(0.81, \mathrm{p}=0.05)$ (Figure 1). sCort values assessed throughout the week presented no significant changes (CV: 72-141\%) (Figure 2). During the CP, no significant differences were observed among the day's neither in $\mathrm{CK}$, sCort and sIgA. When comparing $\mathrm{CP}$ and NCP, higher $\mathrm{CK}$ values were observed in $\mathrm{MD}+2$ in $\mathrm{CP}$ (vs. MD+2 in NCP, ES: 0.27 , $\mathrm{p}<0.01$ ) (Figure 3). No differences between CP and NCP were observed in sCort and sIgA values. TDC (ES: 1.09), HSR (ES: 0.35) and accelerations (ES: 0.36) metrics all showed higher values in MD-1 during CP vs. NCP $(\mathrm{p}<0.05)$ (Table 1$)$.

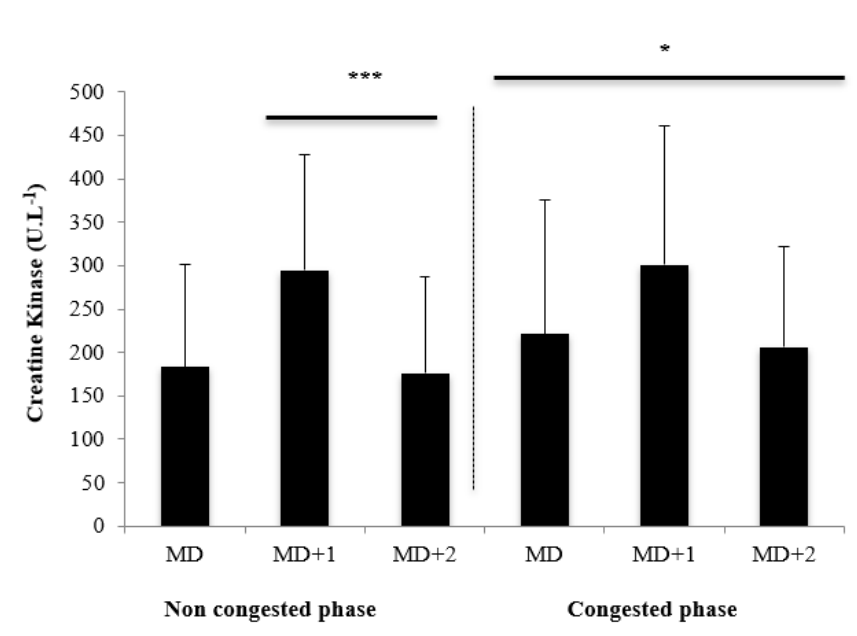

Figure 3: Post-match creatine kinase, during congested and non-congested weeks in elite soccer players. $\mathrm{MD}=$ match day $\mathrm{MD}+1=$ one day after the match $M D+2=$ two days after the match * significant differences $(p<0.05)$

$* * *$ significant differences $(p<0.001)$

\section{Discussion}

The aim of the present study was to compare the variation of CK, sIgA and sCort responses during congested and noncongested periods in elite level soccer players. CK is well reported within literature as an indicator of exercise severity and exerciseinduced muscle damage $[6,30]$ of which post-match increase was reported to be higher in soccer compared to other team sports like basketball, volleyball and handball [31]. Furthermore, CK, Cort and IgA were recently suggested as relevant indicators to monitor training load in elite soccer players [19,22,15]. The present study demonstrated that MD+1 (296 \pm 183 U.L-1) was the day of the week with the highest CK values (similar to MD-3 (283 \pm 185 U.L-1)) (Figure 1). This would highlight how muscular fatigue related to TL was at its highest point $24 \mathrm{~h}$ following the match and three days before the match. Korean soccer players reported higher training-related perceived exertion (RPE) on MD-4 during the competitive season [32]. Similar high RPE were reported on MD-4 and MD-5 in young soccer players, and lower RPE in MD-3 and MD-2 (rest in MD-1). The elevated values of HSR $(0.84 \pm 0.80 \mathrm{~m} . \mathrm{min}-1)$ and number of accelerations $(46.3 \pm 15.4)$ observed in MD-4 in comparisons to all other days, in the present investigation, confirmed that the analysed team followed the same microcycle periodization approach. Recent literature in the area of training specificity and tapering have highlighted similar tapering approaches, suggesting reducing TL as MD approaches to relieve fatigue and increase freshness [33-35]. Recently, it was reported amongst English Premier League soccer players that only MD-1 revealed a significantly reduced tapering effect and TL across a training microcycle when compared with other training days [33]. Additionally, Owen et al. [35] revealed significant differences in physical outputs were found between MD-2, MD-3 and MD-4 highlighting a structured periodized tapered approach $(\mathrm{p}<0.05)$. Furthermore, it was suggested that practitioners can maintain a uniformed and structured TL mesocycle whilst inducing variation of the physical outputs during the microcycle phase. However, it did not involve congested fixture periods in this study.

Days following the match revealed CK values were elevated MD+1 (296 \pm 183 U.L-1 vs. MD: $183 \pm 118$ U.L-1, $p<0.003)$ returning to baseline on MD+2 (176 \pm 111 U.L-1). According to previous research, increased levels of $\mathrm{CK}$ are commonly observed $24 \mathrm{~h}$ post-match, however, further analysis reveals how $\mathrm{CK}$ values generally remain elevated at least $48 \mathrm{~h}$ after the match $(2,17,22,24,39,43)$ which is contrary to our observations. Prematch measures of CK $(\sim 183$ U.L-1) were similar to what was previously reported in elite Greek soccer ( 150 U.L-1) (22), 2nd and 3rd Portuguese divisions ( 180-200 U.L-1) [10,36] French Ligue 1 players ( 230 U.L-1) [37] values reported in 
young Italian Serie A ( 310 U.L-1) [12] and in Premier League under-21 players ( $\sim 343$ U.L-1) [13]. Subsequently, results in the current study revealed lower values on MD+1 ( $\sim 296$ U.L1) compared to all previous reports (from $\sim 600$ to $\sim 1411$ U.L-1), and likewise in MD+2 ( $\sim 176$ U.L-1 in ours vs. $\sim 500$ to $\sim 900$ U.L-1) [10-13,36,37] although only one investigation did not report significant differences between baseline and $\mathrm{MD}+2$ values [37]. Even though CK is known to present high individual and between-match variability (43) it might be suggested that the differences observed within studies were related to the match-related physical and psychological strain. Indeed, it has been recently reported that $\mathrm{CK}$ values $24 \mathrm{~h}$ following the match are associated with the physical activity performed during the match $[38,39]$. Interestingly, the most marked increase in CK values post-exercise was reported in less well-trained subjects [40] and with lesser levels of lower-limb strength in elite level soccer players [6]. Taking these findings into consideration, it might also be suggested that the elite level players used in the present investigation were higher trained than those from compared literature. Furthermore, the investigated matches occurred at the beginning of the season when players just finished the high-TL pre-season period and were supposed to be at their greater shape $[41,42]$ and subsequent lower biochemical markers related to fatigue [43]. It is therefore possible that the matches in the present investigation did not represent a much higher muscular stimulus than the usual training load of these players. This may therefore suggest that if teams and players are trained at a higher level of stimulus, then they may be able to recover from game with greater efficiency.

No evolutions were found in sCort concentrations between pre and post-match assessments (Figure 2). Recently, Souglis et al. [31] reported an increased level of blood cortisol immediately after elite team sports games including soccer, which returned to pre-match values 13 hours after the match. Also, Moreira et al. [16] observed a trend to increase in sCort between pre-and post-match measures in male professional players, but with no significant differences. These results were in accordance with those from the present investigation, which its first postmatch measure was only made $24 \mathrm{~h}$ after the end of the game. Within all observations combines, it seems that sCort might increase immediately after a soccer game, but values might have returned to baseline the day after. Recently, one study reported decreased level of blood cortisol $24 \mathrm{~h}$ and $48 \mathrm{~h}$ after a soccer match, compared to pre-match values in young soccer players [15]. In this particular investigation, the elevated pre-match levels may have been caused by non-exercise stress, for example environmental and psychological stress can modulate cortisol [44].

The second findings from the present investigation was that $\mathrm{CK}$, and neither sCort nor sIgA, was affected by a congested calendar of competitive matches. Indeed, the levels of CK assessed in MD+2 from the CP (206 \pm 116 U.L-1) were significantly higher than levels assessed in MD+2 from the NCP $(176 \pm 111$
U.L-1, p<0.05, ES: 0.27). Furthermore, the differences observed, with $\mathrm{MD}+1$ being higher than MD+2 in NCP, were not anymore observed in the CP. CP have been associated with unchanged physical and technical performance during elite soccer matches, even when periods were prolonged for several months $[45,46]$. However, the literature reported an increase in injury occurrence in association with fixtures congestion [21,47]. Recently, Mohr et al. [22] reported higher CK responses when playing two matches in three days, than in four. The present report gave further and novel information that showed the impact of playing two matches in three to four days (vs. five or more) on muscle damages, which, as a supposed induced cumulated fatigue, were more elevated $48 \mathrm{~h}$ after a congested fixture than when playing one match in a week with sufficient recovery. The levels of sCort and sIgA remained statistically unchanged in both $\mathrm{CP}$ and NCP. However, it was interesting to observe that sIgA values increased from MD+1 $(292 \pm 157 \mu \mathrm{g} \cdot \mathrm{mL}-1)$ to $\mathrm{MD}+2(333 \pm 243 \mu \mathrm{g}$ mL-1) during NCP and decreased $(304 \pm 193$ to $266 \pm 163 \mu$ g. $\mathrm{mL}-1$, respectively) during $\mathrm{CP}$, even though not significantly ( $p>0.0033$ ). Moreira et al. [49] recently reported a decrease in salivary immune-endocrine markers, like sIgA and testosterone, from the first match of a congested soccer tournament to the last one, in young elite players. They also reported no statistical variations in sCort across the tournament [50]. Earlier, Mortatti et al. [48] also reported no variations in sCort across a period of six matches in 20 days in young soccer players, and a decrease in sIgA in second and last matches. All together, these findings might suggest that a congested competitive calendar in elite soccer players induces fatigue related to muscle damage, mucosal immunity, and anabolism activity, but not hypothalamicpituitary-adrenal axis responses. A limitation associated with the current study is that testosterone was not measured, as such the testosterone: cortisol ratio could not be calculated. This ratio is of interest as it has been reported as an indicator of homeostasis between anabolic and catabolic process in the body [50,51]. Furthermore, the testosterone: cortisol ratio has been associated with overtraining in team sport athletes [14] and could be used to monitor stress and recovery state in soccer $[38,52]$. Interestingly, findings from the current study reveal how the there was significantly higher training load on MD-1 during $\mathrm{CP}$ when compared with the NCP. This finding may be as a result of increased freshness and the reduced training load of MD-2 playing a subconscious role on the application and motivation to train at a greater intensity. Although this is difficult to predict and requires further investigation in the future, the technical staff may also have increased the content somewhat as a way of ensuring the players are prepared for the additional fixture post- a low loading day. Furthermore, it should be highlighted that this increase in workload pre-game may have played a role in the accumulated fatigue in the CP even though the effect size in difference were small for both HSR and accelerations (0.340.36). Even though the workload was slightly increased across the CP vs. NCP the biochemical stress observed through prematch CK assessment was the same. These observations further 
indicate the need from the technical staff to plan and understand the impact CP plays on the fatigue and state of the player in order to manipulate accordingly training workload to increase performance [53].

\section{Limitations}

Ensuring large subject participation within elite level soccer research is extremely difficult. The ability to meet subject inclusion criteria is often challenging due numerous external influences such as suspensions, team selections, injury and illness across an in-season period of testing. Therefore, with respect to this investigation, future research should look to draw from baseline data across more than one team at different levels to show how they can be compared across. Ensuring a larger subject pool in addition to increasing the sampling period and getting a same number of matches collected within the periods in order to add greater strength to the association demonstrated across CP vs. NCP would be beneficial however, although understanding this as a priority, unfortunately this is not always possible when conducting scientific studies at the elite level of a sporting organization. Furthermore, it may be beneficial in future research to examine a similar experimentation method across a range of competitive levels (i.e. professional, youth and amateur) as a way of determining key differences at varying playing levels and allow the findings of this to increase knowledge of changes of differing proficiencies. It should be highlighted that a limitation of the study was not including a control group. This is something that future research should try and include, however based on the fact that the study group was a group of elite professional soccer players, the resources available were allocated for the primary professional team.

\section{Conclusion}

The purpose of this investigation was to explore the evolution of biochemical responses of CK, salivary IgA and cortisol during the in-season competitive phase, and analyse the various responses associated with congested vs. non-congested competitive phases in relation to player's post-match fatigue kinetics. The findings of this study may further enhance the capability of individuals involved within the preparation of elite players to manage specific congested or non-congested phases of the competitive season to produce improved decisions as the players in the present study showed impairments in postmatch CK levels during CP. Conclusions drawn from the current investigation suggests that congested competitive periods at the elite level of the game induce significant changes in biochemical stress responses (i.e. muscle damage). As a result of these findings individuals involved with the physical preparation of such players should understand the demands imposed on players in congested fixture periods and adequately adjust preparation and squad rotation accordingly.

\section{Practical applications}

At the elite level of the game professional soccer training and competitive match play induces a significant chronic stress on the body, which influences the biochemical responses of players [1]. Such continued demands and fluctuating physiological changes predispose players to health, wellbeing and performance risks based on the high intensity and energy expending nature of the sport. This novel investigation is the first study to have examined the relationship of biochemical responses based on assessment of salivary cortisol and CK across congested and non-congested periods at the elite level of the game. Based on the data collected in the current study, it is recommended manipulation of the training intensity, recovery strategies and the intelligent integration of squad rotation processes be present as a way of maximising performance whilst reducing the risk of chronic fatigue and injury risk. This study may open up the discussion area of additional ways to include monitoring and assessment of players through congested periods of the competitive season and be considered as one of many factors in injury prevention. Greater focus should be placed on the training intensity and volume over a longer-term, especially approaching congested periods of the season with the aim of ensuring the potential reduction of fatigue that may lead to overuse injuries. Therefore, regularly monitoring biochemical changes (i.e. CK) within the preparation period and across the competitive season to try and ensure optimal player preparation state is something that should be highly considered.

\section{Acknowledgement}

The authors would like to thank all the players, performance, sport science and medical staff at the professional football club involved within this study for their commitment and professionalism throughout the testing, training and assessment procedures.

\section{References}

1. Owen AL, Cossio Bolaños MA, Mendes B, Rouissi M, Chtara M, et al. (in press). Post-seasonal hematological profiles in response to highly competitive match-play loads within elite top-level European soccer players. Open Access Journal of Sports Medicine.

2. Bangsbo J, Iaia FM, Krustrup P (2007) Metabolic fatigue in soccer. Int J Sports Physiol Perform 2(2): 111-127.

3. Stolen T, Chamari K, Castagna C, Wisloff U (2005) Physiology of soccer: an update. Sports Medicine 35(6): 501-536.

4. Brancaccio P, Lippi G, Maffulli N (2010) Biochemical markers of muscular damage. Clin Chem Lab Med 48(6): 757-767.

5. Djaoui L, Haddad M, Chamari K, Dellal A (2017) Monitoring training load and fatigue in soccer players with physiological markers. Physiol Behav 181: 86-94

6. Owen A, Dunlop G, Rouissi M, Chtara M, Paul D, et al. (2015) The relationships between lower-limb strength and match-related muscle damage in elite level professional European soccer players. J Sports Sci 33(20): 2100-2105.

7. Akenhead R, Harley JA, Tweddle S (2016) Examining the external training load of an English Premier League football team with special reference to acceleration. J Strength Cond Res 30(9): 2424-2432.

8. Raastad T, Owe SG, Paulsen G, Enns D, Overguard K, et al. (2010) Changes in calpain activity, muscle structure, and function after eccentric exercise. Journal of Medicine and Science in Sports and Exercise 42(1): 86-95. 
9. Young WB, Hepner J, Robbins DW (2012) Movement demands in Australian rules football as indicators of muscle damage. J Strength Cond Res 26(2): 492-496.

10. Ascensao A, Rebelo A, Oliveira E, Marques F, Pereira L, et al. (2008) Biochemical impact of a soccer match-analysis of oxidative stress and muscle damage markers throughout recovery. Clin Biochem 41(1011): 841-851.

11. Ispirlidis I, Fatouros IG, Jamurtas AZ, Nikolaidis MG, Michailidis I, et al. (2008) Time-course changes in inflammatory and performance responses following a soccer game. Clin J Sport Med 18(5): 423-431.

12. Rampinini E, Bosio A, Ferraresi I, Petruolo A, Morelli A, et al. (2011) Match-related fatigue in soccer players. Med Sci Sports Exerc 43(11): 2161-2170.

13. Russell M, Northeast J, Atkinson G, Shearer DA, Sparkes W, et al. (2015) The between-match variability of peak power output and Creatine Kinase responses to soccer match-play. Journal of Strength and Conditioning Research 29(8): 2079-2085.

14. Banfi G, Dolci A (2006) Free testosterone/cortisol ratio in soccer: usefulness of a categorization of values. J Sports Med Phys Fitness 46(4): 611-616

15. Romagnoli M, Sanchis Gomar F, Alis R, Risso Ballester J, Bosio A, et al. (2016) Changes in muscle damage, inflammation, and fatigue-related parameters in young elite soccer players after a match. J Sports Med Phys Fitness 56(10): 1198-1205.

16. Moreira A, Arsati F, De Oliveira Lima Arsati YB, Silva DA, Araujo VC (2009) Salivary cortisol in top-level professional soccer players. European Journal of Applied Physiology 106(1): 25-30.

17. Edwards DA, Casto KV (2013) Women's intercollegiate athletic competition: cortisol, testosterone, and the dual-hormone hypothesis as it relates to status among teammates. Horm Behav 64(1): 153-160.

18. Cunniffe B, Griffiths H, Proctor W, Davies B, Baker JS, et al. (2011) Mucosal immunity and illness incidence in elite rugby union players across a season. Med Sci Sports Exerc 43(3): 388-397.

19. Morgans R, Orme P, Anderson L, Drust B, Morton JP (2014) An intensive winter fixture schedule induces a transient fall in salivary IgA in English premier league soccer players. Research in Sport Medicine 22(5): $346-$ 354

20. Bengtsson H, Ekstrand J, Hagglund M (2013) Muscle injury rates in professional football increase with fixture congestion: an 11-year follow-up of the UEFA Champions League injury study. British Journal of Sports Medicine 47(12): 743-747.

21. Dellal A, Lago Peñas C, Rey E, Chamari K, Orhant E (2015) The effects of a congested fixture period on physical performance, technical activity and injury rate during matches in a professional soccer team. Br J Sports Med 49(6): 390-394.

22. Mohr M, Draganidis D, Chatzinikolau A, Barbero Alvarez JC, Castagna et al. (2016) Muscle damage, inflammatory, immune and performance responses to three games in 1 week in competitive male players. Eur Appl Physiol 116(1): 179-193.

23. Rey E, Lago Penas C, Lago Ballesteros J, Casais L, Dellal A (2010) The effect of a congested fixture period on the activity of elite soccer players. Biology of Sport 27: 181-185.

24. Coelho DB, Morandi RF, De Melo MA, Silami Garcia E (2011) Creatine kinase kinetics in professional soccer players during a competitive season. Cinética da creatina quinase em jogadores de futebol profissional em uma temporada competitive. Revista Brasileira de Cineantropometria \& Desempenho Humano 13(3): 189-194.

25. Trewin J, Meylan C, Varley MC, Cronin J (2018) The match-to-match variation of match-running in elite female soccer. Journal of Science and Medicine in Sport 21(2): 196-201.
26. Varley MC, Fairweather IH, Aughey RJ (2012) Validity and reliability of GPS for measuring instantaneous velocity during acceleration, deceleration, and constant motion. Journal of Sports Sciences 30(2): 121-127.

27. Dunbar J, Jehanil A, Hazell G (2015) Evaluation of a new point care quantitative cube reader for salivary analysis in the English premier league soccer environment. British Journal of Sports Medicine 49(2): A2-A3.

28. Fahlman MM, Engels HJ (2005) Mucosal IgA \& URTI in American college football players: A year longitudinal study. Med Sci Sports Exerc 37(3): 374-380.

29. Cohen J (1988) Statistical power analysis for the behavioural sciences $2^{\text {nd }}($ edn.), Hillsdale, NJ: Lawrence Erlbaum.

30. Chevion S, Moran DS, Heled Y, Shani Y, Regev G, et al. (2003) Plasma antioxidant status and cell injury after severe physical exercise. Proc Natl Acad Sci USA 100(9): 5119-5123.

31. Souglis A, Bogdanis GC, Giannopoulou I, Papadopoulos C, Apostolidis $\mathrm{N}$ (2015) Comparison of inflammatory responses and muscle damage indices following a soccer, basketball, volleyball and handball game at an elite competitive level. Research in Sports Medicine 23(1): 59-72.

32. Jeong TS, Reilly T, Morton J, Bae SW, Drust B (2011) Quantification of the physiological loading of one week of pre-season and one week of in season training in professional soccer players. J Sports Sci 29(11): 1161-1166.

33. Malone JJ, Di Michele R, Morgans R, Burgess D, Morton JP, et al. (2015) Seasonal training-load quantification in elite English premier league soccer players. Int J Sports Physiol Perform 10(4): 489-497.

34. Owen AL, Dunlop G, Rouissi M, Haddad M, Mendes B, et al. (2016) Analysis of positional training toads (ratings of perceived exertion) during various-sided games in European professional soccer players. International Journal of Sport Science and Coaching 11(3): 1-8.

35. Owen AL, Lagos Penas C, Gómez MA, Mendes B, Dellal A (2017) Analysis of a training mesocycle and positional quantification in elite European soccer players. International Journal of Sport Science and Coaching 12(5): 1-8.

36. Magalhaes J, Rebelo A, Oliveira E, Silva JR, Marques F, et al. (2010) Impact of Loughborough intermittent shuttle test versus soccer match on physiological, biochemical and neuromuscular parameters. Eur J Appl Physiol 108(1): 39-48.

37. Djaoui L, Diaz Cidncha G, Hautier C, Dellal A (2016) Kinetic post-match fatigue in professional and youth soccer players during the competitive period. Asian J Sports Med 7(1): e28267.

38. Thorpe R, Sunderland C (2012) Muscle damage, endocrine, and immune marker response to a soccer match. Journal of Strength and Conditioning Research 26(10): 2783-2790.

39. Russell M, Sparkes W, Northeast J, Cook CJ, Kilduff L (2016) Relationships between match activities and peak power output and creatine kinase responses to professional reserve team soccer matchplay. Hum Mov Sci 45: 96-101.

40. Maxwell JH, Bllor CM (1981) Effects of conditioning on exertional rhabdomyolysis and serum creatine kinase after severe exercise. Enzyme 26(4): 177-181.

41. Bangsbo J (1994) The physiology of soccer-With special reference to intense intermittent exercise. Acta Physiol Scand Suppl 619: 1-155.

42. Reilly T (2007) The training process. In: Reilly T, ed. The Science of Training-Soccer: A Scientific Approach to Developing Strength, Speed and Endurance. London: Routledge. Pp. 1-19.

43. Silva JR, Rebelo A, Marques F, Pereira L, Seabra A, et al. (2014) Biochemical impact of soccer: an analysis of hormonal, muscle damage, 
and redox markers during the season. Appl Physiol Nutr Metab 39(4): $432-438$

44. Passelergue P, Lac G (1999) Saliva cortisol, testosterone and T/C ratio variations during a wrestling competition and during the postcompetitive recovery period. International Journal of Sports Medicine 20(2): 109-113.

45. Carling C, Gregson W, McCall A, Moreira A, Wong DP, et al. (2015) Match running performance during fixture congestion in elite soccer research issues and future directions. Sports Med 45(5): 605-613.

46. Djaoui L, Wong DP, Pialoux V, Hautier C, Da Silva CD, et al. (2014) Physical activity during a prolonged congested period in a top-class European football team. Asian J Sports Med 5(1): 47-53.

47. Dupont G, Nedelec M, McCall A, McCormack D, Berthoin S, et al. (2010) Effect of 2 soccer matches in a week on physical performance and injury rate. Am J Sports Med 38(9): 1752-1758.

48. Mortatti A, Moreira A, Aoki MS, Crewther B, Castagna C, et al. (2012) Effect of competition on salivary cortisol, immunoglobulin A, and upper respiratory tract infections in elite young soccer players. J Strength Cond Res 26(5): 1396-1401.
49. Moreira A, Bradley P, Carling C, Arruda AF, Spigolon LM, et al. (2016) Effect of a congested match schedule on immune-endocrine responses, technical performance and session-RPE in elite youth soccer players. J Sports Sci 34(24): 2255-2261.

50. Bambino TH, Hsueh AJ (1981) Direct inhibitory effect of glucocorticoids upon testicular luteinizing hormone receptor and steroidogenesis in vivo and in vitro. Endocrinology 108(6): 2142-2148.

51. Cumming DC, Quigley ME, Yen SS (1983) Acute suppression of circulating testosterone levels by cortisol in men. J Clin Endocrinol Metab 57(3): 671-673.

52. Michailidis Y (2014) Stress hormonal analysis in elite soccer players during a soccer season. Journal of Sport and Health Science 3(4): 279 283

53. Impellizzeri FM, Rampinini E, Coutts AJ, Sassi A, Marcora SM (2004) Use of RPE-based training load in soccer. Med Sci Sports Exerc 36(6): 1042-1047.

\section{Your next submission with Juniper Publishers} will reach you the below assets

- Quality Editorial service

- Swift Peer Review

- Reprints availability

- E-prints Service

- Manuscript Podcast for convenient understanding

- Global attainment for your research

- Manuscript accessibility in different formats

(Pdf, E-pub, Full Text, Audio)

- Unceasing customer service

Track the below URL for one-step submission https://juniperpublishers.com/online-submission.php 